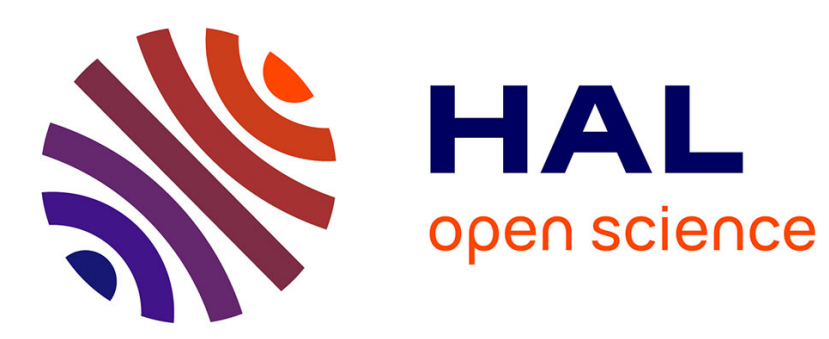

\title{
Highlights of the Flame Acceleration in a Confined Nonuniform H2/O2/N2 Mixture
}

\author{
Jérôme Daubech, Isabelle Sochet
}

\section{To cite this version:}

Jérôme Daubech, Isabelle Sochet. Highlights of the Flame Acceleration in a Confined Nonuniform H2/O2/N2 Mixture. Process Safety Progress, 2010, 29 (3), pp.224-230. 10.1002/prs.10338 . hal00606083

\section{HAL Id: hal-00606083 https://hal.science/hal-00606083}

Submitted on 5 Jul 2011

HAL is a multi-disciplinary open access archive for the deposit and dissemination of scientific research documents, whether they are published or not. The documents may come from teaching and research institutions in France or abroad, or from public or private research centers.
L'archive ouverte pluridisciplinaire HAL, est destinée au dépôt et à la diffusion de documents scientifiques de niveau recherche, publiés ou non, émanant des établissements d'enseignement et de recherche français ou étrangers, des laboratoires publics ou privés. 


\section{AIChE - Process Safety Progress Journal}

Copy of e-mail Notification

AIChE - Process Safety Progress Published by John Wiley \& Sons, Inc.

Dear Author,

YOUR PAGE PROOFS ARE AVAILABLE IN PDF FORMAT; please refer to this URL address http://kwglobal.co.in/jw/retrieval.aspx?pwd=150206fb7c73

Login: your e-mail address

Password: $150206 \mathrm{fb} 7 \mathrm{c73}$

The site contains 1 file. You will need to have Adobe Acrobat Reader software to read these files. This is free software and is available for user downloading at http://www.adobe.com/products/acrobat/readstep.html. Alternatively, if you would prefer to receive a paper proof by regular mail, please contact Prasanth/Sankar/Balaji(email: wileysupport@kwglobal.com, phone: +91 (44) 4205-8888 (ext.310). Be sure to include your article number.

This file contains:

Author Instructions Checklist

Acrobat Notes Instructions

Reprint Order form

Fax Coversheet

A copy of your page proofs for your article

After printing the PDF file, please read the page proofs carefully and:

1) indicate changes or corrections in the margin of the page proofs;

2) answer all queries (footnotes A,B,C, etc.) on the last page of the PDF proof;

3) proofread any tables and equations carefully;

4) check that any Greek, especially "mu", has translated correctly.

Special Notes:

Please return hard copy corrections and reprint order form to Wiley via express/overnight service or fax as soon as possible (to Arthur Baulch; see address and numbers below). If you fax your corrections, please include a cover page detailing the corrections as changes may be distorted during transmission.

Your article will be published online via our EarlyView service after correction receipt. Your prompt attention to and return of page proofs is crucial to faster publication of your work. Thank you for your cooperation. 


\section{AIChE - Process Safety Progress Journal}

Copy of e-mail Notification

Return to:

Arthur Baulch

John Wiley \& Sons, Inc.

111 River Street, MS 8-02

Hoboken, NJ 07030

U.S.A.

(See fax number and e-mail address below.)

If you experience technical problems, please contact Prasanth/Sankar/Balaji(e-mail: wileysupport@kwglobal.com, phone: +91 (44) 4205-8888 (ext.310). Be sure to include your article number.

If you have any questions regarding your article, please contact me. PLEASE ALWAYS INCLUDE YOUR ARTICLE NO. ( 325 ) WITH ALL CORRESPONDENCE.

This e-proof is to be used only for the purpose of returning corrections to the publisher.

Sincerely,

Arthur Baulch

Senior Production Editor

John Wiley \& Sons, Inc.

E-mail: abaulch@wiley.com

Tel: 201-748-6971

Fax: 201-748-6182 


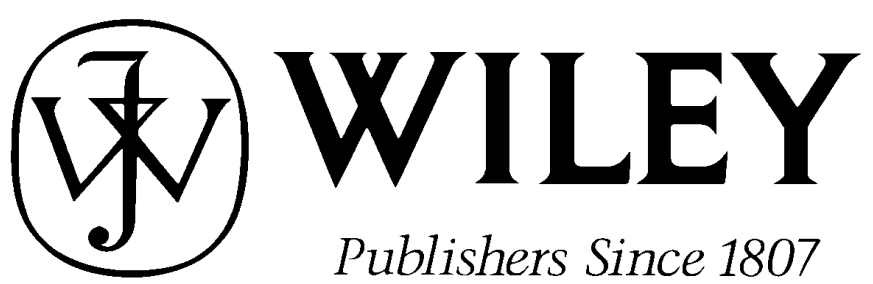

\section{River Street, Hoboken, NJ 07030}

***IMMEDIATE RESPONSE REQUIRED***

Please follow these instructions to avoid delay of publication.

\section{READ PROOFS CAREFULLY}

- This will be your only chance to review these proofs.

- Please note that the volume and page numbers shown on the proofs are for position only.

ANSWER ALL QUERIES ON PROOFS (Queries for you to answer are attached as the last page of your proof.)

- Mark all corrections directly on the proofs. Note that excessive author alterations may ultimately result in delay of publication and extra costs may be charged to you.

CHECK FIGURES AND TABLES CAREFULLY (Color figures will be sent under separate cover.)

- Check size, numbering, and orientation of figures.

- All images in the PDF are downsampled (reduced to lower resolution and file size) to facilitate Internet delivery. These images will appear at higher resolution and sharpness in the printed article.

- Review figure legends to ensure that they are complete.

- Check all tables. Review layout, title, and footnotes.

\section{COMPLETE REPRINT ORDER FORM}

- $\quad$ Fill out the attached reprint order form. It is important to return the form even if you are not ordering reprints. You may, if you wish, pay for the reprints with a credit card. Reprints will be mailed only after your article appears in print. This is the most opportune time to order reprints. If you wait until after your article comes off press, the reprints will be considerably more expensive.

RETURN $\square$ PROOFS $\square$ REPRINT ORDER FORM $\square$ CTA (If you have not already signed one)

\section{RETURN WITHIN 48 HOURS OF RECEIPT VIA FAX TO 201-748-8852}

\section{QUESTIONS?}

Arthur Baulch, Senior Production Editor

Phone: 201-748-6971

E-mail: abaulch@wiley.com

Refer to journal acronym and article production number 


\section{Softproofing for advanced Adobe Acrobat Users - NOTES tool}

NOTE: ACROBAT READER FROM THE INTERNET DOES NOT CONTAIN THE NOTES TOOL USED IN THIS PROCEDURE.

Acrobat annotation tools can be very useful for indicating changes to the PDF proof of your article. By using Acrobat annotation tools, a full digital pathway can be maintained for your page proofs.

The NOTES annotation tool can be used with either Adobe Acrobat 6.0 or Adobe Acrobat 7.0. Other annotation tools are also available in Acrobat 6.0, but this instruction sheet will concentrate on how to use the NOTES tool. Acrobat Reader, the free Internet download software from Adobe, DOES NOT contain the NOTES tool. In order to softproof using the NOTES tool you must have the full software suite Adobe Acrobat Exchange 6.0 or Adobe Acrobat 7.0 installed on your computer.

\section{Steps for Softproofing using Adobe Acrobat NOTES tool:}

1. Open the PDF page proof of your article using either Adobe Acrobat Exchange 6.0 or Adobe Acrobat 7.0. Proof your article on-screen or print a copy for markup of changes.

2. Go to Edit/Preferences/Commenting (in Acrobat 6.0) or Edit/Preferences/Commenting (in Acrobat 7.0) check "Always use login name for author name" option. Also, set the font size at 9 or 10 point.

3. When you have decided on the corrections to your article, select the NOTES tool from the Acrobat toolbox (Acrobat 6.0) and click to display note text to be changed, or Comments/Add Note (in Acrobat 7.0).

4. Enter your corrections into the NOTES text box window. Be sure to clearly indicate where the correction is to be placed and what text it will effect. If necessary to avoid confusion, you can use your TEXT SELECTION tool to copy the text to be corrected and paste it into the NOTES text box window. At this point, you can type the corrections directly into the NOTES text box window. DO NOT correct the text by typing directly on the PDF page.

5. Go through your entire article using the NOTES tool as described in Step 4.

6. When you have completed the corrections to your article, go to Document/Export Comments (in Acrobat 6.0) or Comments/Export Comments (in Acrobat 7.0). Save your NOTES file to a place on your harddrive where you can easily locate it. Name your NOTES file with the article number assigned to your article in the original softproofing e-mail message.

\section{When closing your article PDF be sure NOT to save changes to original file.}

8. To make changes to a NOTES file you have exported, simply re-open the original PDF proof file, go to Document/Import Comments and import the NOTES file you saved. Make changes and reexport NOTES file keeping the same file name.

9. When complete, attach your NOTES file to a reply e-mail message. Be sure to include your name, the date, and the title of the journal your article will be printed in. 


\section{John Wiley \& Sons, Inc.}

\section{REPRINT BILLING DEPARTMENT • 111 RIVER STREET • HOBOKEN, NJ 07030 \\ PHONE: (201) 748-8789; FAX: (201) 748-6326 \\ E-MAIL: reprints @ wiley.com \\ PREPUBLICATION REPRINT ORDER FORM}

Please complete this form even if you are not ordering reprints. This form MUST be returned with your corrected proofs and original manuscript. Your reprints will be shipped approximately 4 weeks after publication. Reprints ordered after printing are substantially more expensive.

JOURNAL:PROCESS SAFETY PROGRESS

VOLUME

ISSUE

TITLE OF MANUSCRIPT

MS. NO

NO. OF PAGES

$\operatorname{AUTHOR}(\mathrm{S})$

\section{REPRINTS 81/4 X11}

\begin{tabular}{l|ccccc} 
No. of Pages & 100 Reprints & 200 Reprints & 300 Reprints & 400 Reprints & 500 Reprints \\
\hline & $\$$ & $\$$ & $\$$ & $\$$ & $\$$ \\
$1-4$ & 336 & 501 & 694 & 890 & 1,052 \\
$5-8$ & 469 & 703 & 987 & 1,251 & 1,477 \\
$9-12$ & 594 & 923 & 1,234 & 1,565 & 1,850 \\
$13-16$ & 714 & 1,156 & 1,527 & 1,901 & 2,273 \\
$17-20$ & 794 & 1,340 & 1,775 & 2,212 & 2,648 \\
$21-24$ & 911 & 1,529 & 2,031 & 2,536 & 3,037 \\
$25-28$ & 1,004 & 1,707 & 2,267 & 2,828 & 3,388 \\
$29-32$ & 1,108 & 1,894 & 2,515 & 3,135 & 3,755 \\
$33-36$ & 1,219 & 2,092 & 2,773 & 3,456 & 4,143 \\
$37-40$ & 1,329 & 2,290 & 3,033 & 3,776 & 4,528
\end{tabular}

** REPRINTS ARE ONLY AVAILABLE IN LOTS OF 100. IF YOU WISH TO ORDER MORE THAN 500 REPRINTS, PLEASE CONTACT OUR REPRINTS DEPARTMENT AT (201)748-8789 FOR A PRICE QUOTE.

\section{COVERS}

100 Covers - $\$ 90$

400 Covers - $\$ 255$

\section{- 200 Covers - $\$ 145$}

- $\quad 500$ Covers - $\$ 325$
- 300 Covers - $\$ 200$

- Additional 100s - $\$ 65$

$\square$ Please send me

reprints of the above article at.

Generic covers of the above journal at.

Pleaseadd appropriate State and Local Tax \{ Tax ExemptNo.

Please add 5\% Postage and Handling.

TOTAL AMOUNT OF ORDER**

**International orders must be paid in U.S. currency and drawn on a U.S. bank

Please check one: Check enclosed

If credit card order, charge to: American Express

CreditCardNo.

Bill To:

Name

Address/Institution

Purchase Order No.
Bill me Credit Card

Visa MasterCard Discover

$\$$
$\$$
$\$$
Exp.Date

\section{Ship To:}

Name Address/Institution 


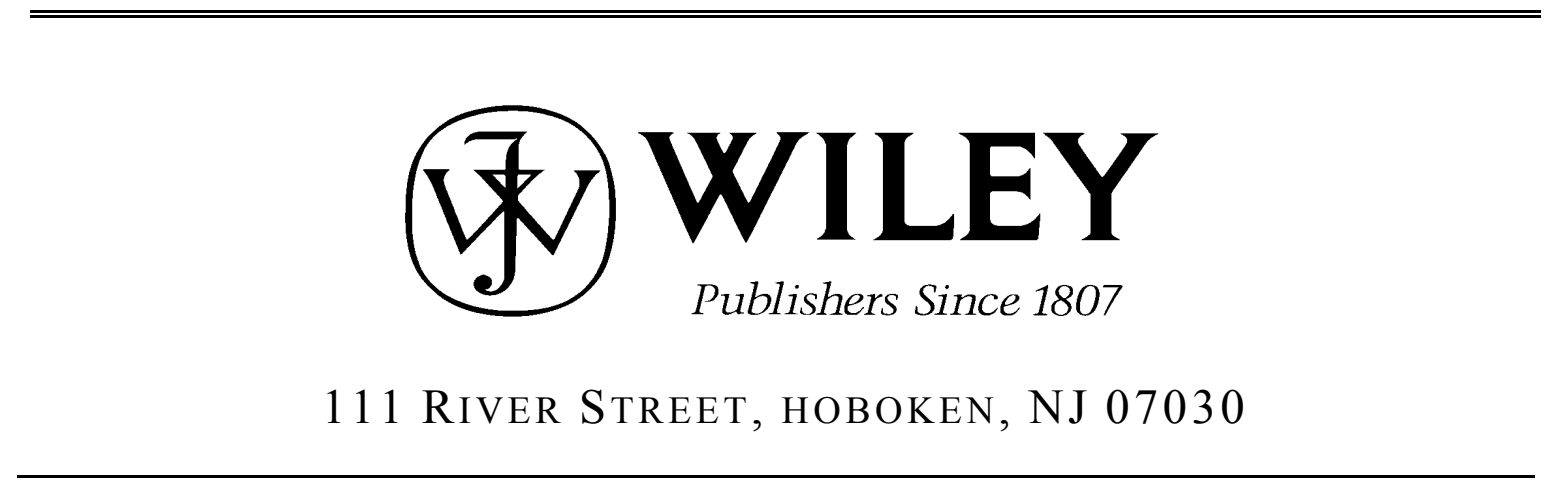

Telephone Number:

- Facsimile Number:

$\begin{aligned} \text { To: } & \text { Arthur Baulch } \\ \text { Company: } & \\ \text { Phone: } & 201-748-6971 \\ \text { Fax: } & 201-748-8852 \\ \text { From: } & \\ \text { Date: } & \end{aligned}$

Pages including this cover

page:

Message:

Re: 


\title{
Highlights of the Flame
}

\section{Acceleration in a Confined} Nonuniform $\mathrm{H}_{2} / \mathbf{0}_{2} / \mathrm{N}_{2}$ Mixture

\author{
J. Daubech, ${ }^{a}$ I. Sochet, ${ }^{b}$ and Ch. Proust ${ }^{a}$ \\ ${ }^{a}$ Institut National de l'Environnement et des Risques (INERIS), Parc Technologique ALATA, BP 2, \\ F60550 Verneuil-en-Halatte, France \\ ${ }^{\mathrm{b}}$ Institut Pluridisciplinaire de Recherche en Ingénierie des Systèmes, Mécanique et Energétique, Ecole Nationale Supérieure \\ d'Ingénieurs de Bourges, 88 bvd Lahitolle, F18020 Bourges Cedex, France; isabelle.sochet@ensi-bourges.fr (for correspondence)
}

Published online 00 Month 2009 in Wiley InterScience (www.interscience.wiley.com). D0I 10.1002/prs.10338

Gaseous explosion models generally assume the gas mixture to be uniform. However, in a real explosion, the vapor cloud may not be homogeneous, and repartitioning of the reactivity inside the cloud can be subject to wide spatial variations. In this work, experimental tests were run to study the flame propagation and acceleration in nonuniform mixtures. Experiments were performed in a long vertical confined tube with a square cross section, composed of four equal sections. A gate valve separated the tube into two parts, and the composition of the gases was different on each side of the valve. The opening of the valve permitted the mixing of gases by molecular diffusion. For nonuniform mixtures, a mode of propagation identical to that seen in uniform mixtures was observed; however, a third phase of propagation was found, in which the flame velocity increased strongly. This increase occurred with higher hydrogen concentration in an upwardpropagating flame. A concentration gradient can appreciably modify the trajectory and acceleration of a flame. Here, however, the incidence of pressure effects remained modest, since the combustion was confined and the final pressure depended mainly on the quantity of reactants available. (C) 2009 American Institute of Chemical Engineers Process Saf Prog 00: 000-000, 2009

Keywords: hydrogen; flame; concentration gradient; nonuniform reactive mixture

\section{INTRODUCTION}

The story of industrialization has been punctuated by explosions, whose frequency and severity have

(c) 2009 American Institute of Chemical Engineers increased with the expansion of industry. Several explosions, such as Flixborough (1974) in the US, La Mède (1992) in France, and more recently, Buncefield (2005) in England, are memorable. The extreme damages incurred by these accidents have considerably affected the neighborhoods and pushed the public authorities to reinforce the regulations governing industries.

Due to public demand, tools for explosion risk analysis and consequences have been progressively developed. These tools are based on observations, analysis of past accidents, or large scale experiments. Developed in the 70s and 80s, the Multi-Energy method [1] serves as a common tool of analysis. Although related tools have become more and more predictive, important simplifications have been made, such as assuming a homogeneous combustible cloud for the Multi-Energy method. However, in real situations, heterogeneities exist. For instance, turbulent jets, induced by massive leaks, are characterized by a much larger concentration near the breach than further downstream. Such leaks produce a significantly nonuniform mixture. Simple simulations [2] show that assuming an equivalent homogenous mixture underestimates damaging effects. Moreover, this method was used in the Buncefield postaccident analysis. It predicted 20-50 mbar of overpressure on buildings, whereas the postaccident analysis revealed magnitudes of overpressure around 700-1,000 mbar [3]. The propagation of an explosion in a space with a varied blockage ratio does not seem sufficient to explain this discrepancy in the overpressures, and one explanation advocated by the Britannic expert committee is cloud heterogeneity. 

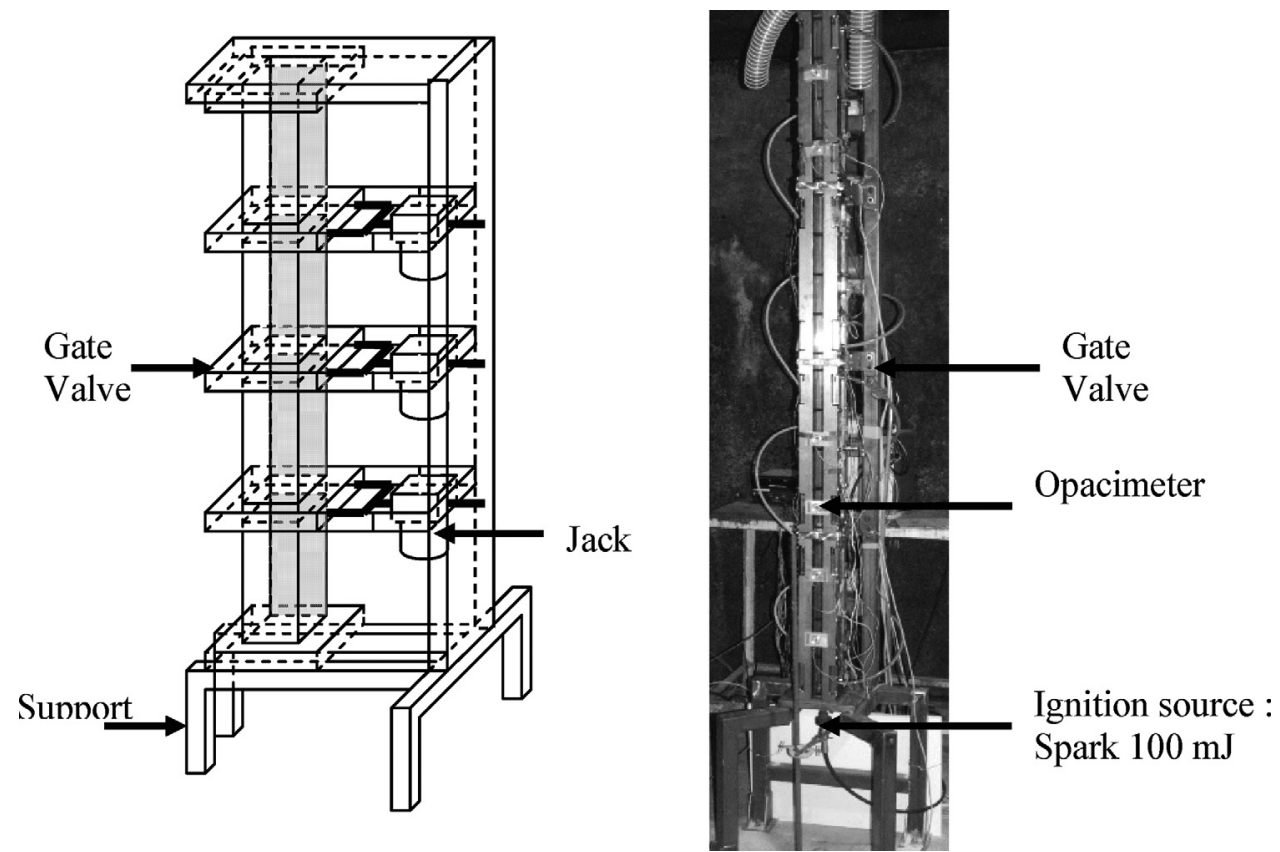

Figure 1. Global view of experimental set-up. [Color figure can be viewed in the online issue, which is available at www.interscience.wiley.com.]

Direct experimental works can assist in the confirmation of this assumption. Indeed, Girard et al. [4] noted a multiplication of maximum overpressure by a factor of three for a flame propagation in two mixtures of different equivalence ratios created by concentric soap bubbles, as well as an important increase of flame propagation speed. A modification of flame propagation speed has also been observed by Karim and Panlilio [5], who noted an increase of $70 \%$ for a flame propagating in a vertical open tube filled by a stratified methane/air mixture. The conclusions of Whitehouse et al. [6] are the same for a hydrogen/air flame. In a closed tube, they also noted an important increase in the maximum overpressure. For a freepropagation flame, Sochet et al. [7] showed that explosion effects are linked to the history of the flame through the cloud and that a concentration gradient may significantly modify the pressure evolution, maximum levels reached, and impulse. Furthermore, the effects of cloud heterogeneities are linked to modifications of the fundamental parameters of combustion, such as expansion ratio and laminar flame velocity. The variations generate a differential acceleration between rich and poor zones, with important modifications of the flame front surface. Hirano et al. [8] confirmed that the differential in expansion velocity induced by a heterogeneous mixture creates an increase of flame front area compared with the equivalent homogeneous mixture. This increase can be added to the effect of cloud heterogeneities, suggesting that the dynamics of flame can affect the kinematics of flame.

An analysis carried out in a previous paper [9] highlighted the influence of the acoustic wave interaction on the flame front and the influences of ther- mal losses to and vapor condensation on the walls on the pressure signal and the mechanism of flame propagation. Taking these effects into account, in this study, we aimed to analyze the situation in the case of a nonuniform mixture.

\section{EXPERIMENTAL SET-UP}

To carry out this study, a special setup was designed. We needed a very careful control of the initial conditions, including the repartition of the reactants. If any convection current were to appear, erratic pockets of mixture could be produced. Consequently, the diameter of the tube needed to be kept small (a few centimeters) so that the formation of gradients could result from molecular diffusion. It was further estimated that a length of tube on the order of $1 \mathrm{~m}$ would permit simulation of the range of reactivity gradients likely to be produced in practical situations $(0.1-1 \mathrm{~m})$.

The tested setup was a 2 -m-long tube, to simulate the range of reactivity gradients that might appear in industry. The sides consisted of $0.03-\mathrm{m}$-long square sections (Figure 1) to limit the possible convection effects. The specifications of the setup were that it should be transparent and resistant to a high-pressure explosion (around 150 bar). Gate valves separated the tube into four equal sections. Each section of the tube was composed of three PMMA walls and one aluminum wall set in a metallic skeleton. Gas tightness was ensured by the application of silicone putty. The skeleton provided support for all of the mechanical stresses.

The gate valves (Figure 2) were two steel shells in which a thin aluminum sheet slides. The composition of the gases was different on both sides of the valve. 


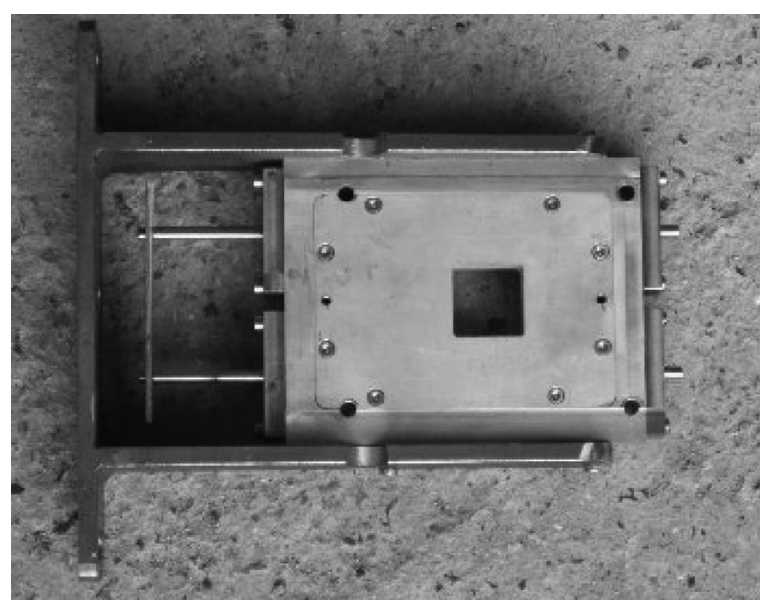

Figure 2. Gate valve. [Color figure can be viewed in the online issue, which is available at www. interscience.wiley.com.]

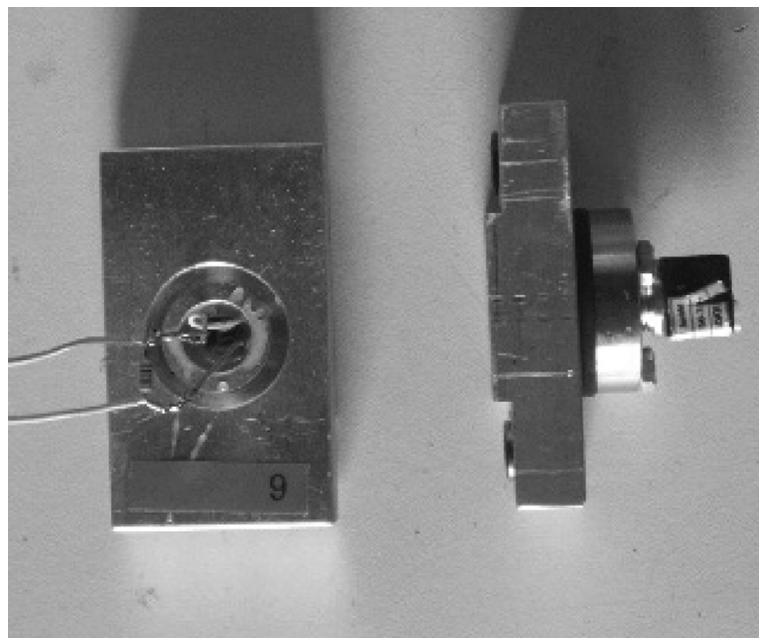

Figure 3. Opacimeters. [Color figure can be viewed in the online issue, which is available at www. interscience.wiley.com.]

The opening of the valve permitted the mixing of gases by molecular diffusion.

A special effort was made to develop the instrumentation necessary for conveniently interpret the tests; specifically, an opacimeter system consisting of a laser diode and a photovoltaic cell fixed on two aluminum supports magnetically mounted on the metallic skeleton was employed (Figure 3). Eight opacimeters were distributed along the tube, with dual functions. They allowed detection of the flame by a modification of a luminous laser signal detected by the photovoltaic cell, consequently allowing us to obtain both the flame speed and trajectory. Moreover, this allowed deduction of the gas mixing ratio. Nanoparticles of ammonium chloride were added to only one part of the tube, and the particles diffused out with the gases after the opening of the gate valve. The "opacity" of the gas changed according to the

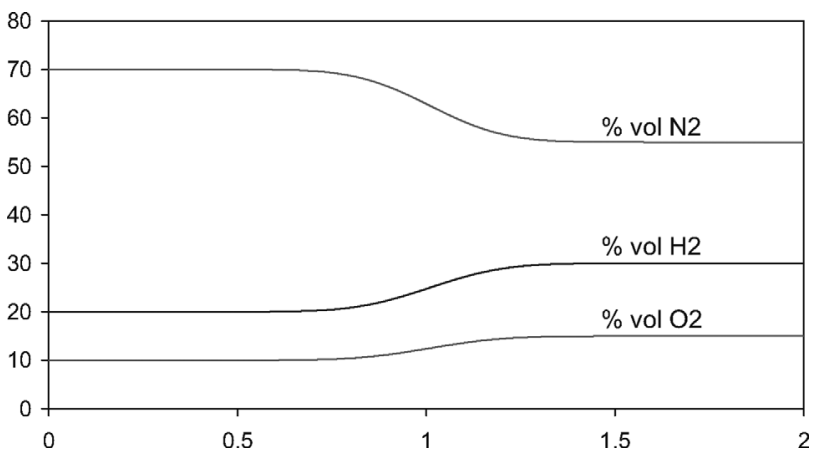

Figure 4. Distribution of species in the tube after 10 min of diffusion. [Color figure can be viewed in the online issue, which is available at www.interscience. wiley.com.]

mixing and was detected by measuring the transmittance at each detector location. An experimental calibration law links the light attenuation ratio and the gas mixing ratio.

A second optical technique was developed to observe the flame area. It consisted of illuminating a thin slab of the tube with an argon ion laser via a rotating mirror. During its propagation, the flame dissociates the ammonium chloride particles without modifying the combustion. As green light is diffused by ammonium chloride, the flame area can be detected via high-speed video to the threshold between high- and low-contrast regions. Pressure was measured by a classical piezoresistive gauge. One pressure gauge was located at the middle of each section. Hence, pressure gauge 1 was at a distance of $0.25 \mathrm{~m}$, pressure gauge 2 at $0.75 \mathrm{~m}$, pressure gauge 3 at $1.25 \mathrm{~m}$, and pressure gauge 4 at $1.75 \mathrm{~m}$ from the bottom.

We considered a nonuniform mixture with an average nitrogen ratio of $62.5 \%$. This was accomplished by setting in contact the upper part $(1 \mathrm{~m})$ of the tube, filled with mixture M3 (30\% vol. $\mathrm{H}_{2}+15 \% \mathrm{O}_{2}$ $\left.+55 \% \mathrm{~N}_{2}\right)$, with the lower part $(1 \mathrm{~m})$ of the tube filled with mixture M1 $\left(20 \% \mathrm{H}_{2}+10 \% \mathrm{O}_{2}+70 \%\right.$ $\mathrm{N}_{2}$ ). The ignition took place $10 \mathrm{~min}$ after the opening of the valve. The distribution of the species at the ignition time, calculated by Fick's (one-dimensional) law of diffusion, is presented in Figure 4. The gradient zone extends $0.70 \mathrm{~m}$, from 0.65 to $1.35 \mathrm{~m}$.

\section{PRESSURE ANALYSIS}

The pressure signals obtained after ignition of the nonuniform mixture (Figure 4) are reported in Figure 5. There were identical responses in each section. A high-frequency signal of low amplitude (typically 100 mbar at $100 \mathrm{~Hz}$ ), corresponding to the local peaks of $F_{\mathrm{i}}$ overpressure, is superimposed on an envelope of large amplitude at low frequency (typically 3 bar at $10 \mathrm{~Hz}$, between 0 and F). The fitted pressure signals obtained in each section are superimposed, meaning that the pressure was homogeneous in the tube overall. 


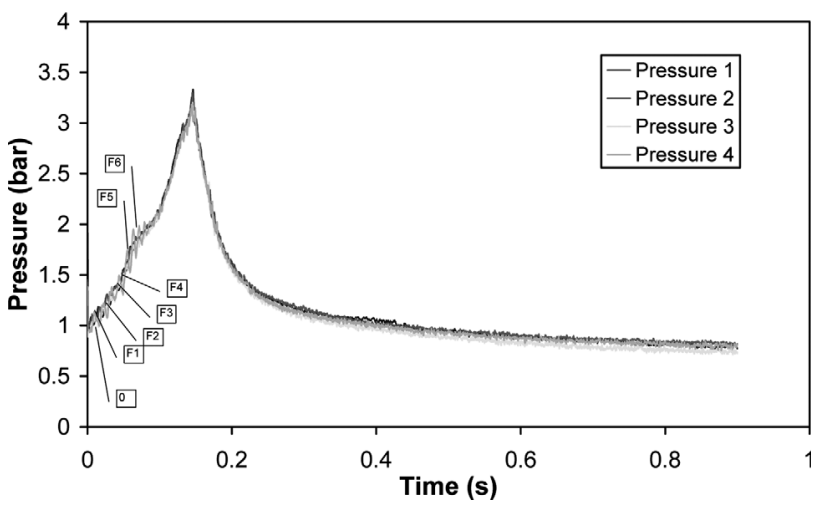

Figure 5. Pressure signals in each section of the tube-nonuniform mixture. [Color figure can be viewed in the online issue, which is available at www.interscience.wiley.com.]

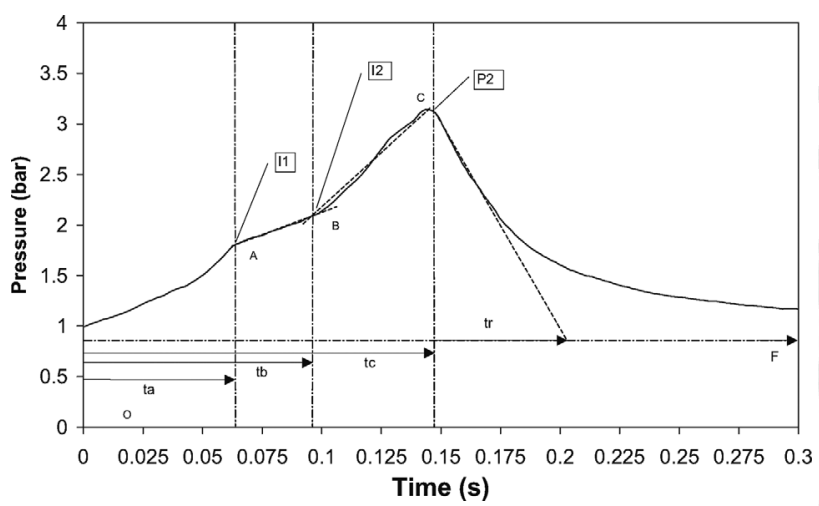

Figure 6. Increase in size of the pressure signal between 0 and $0.3 \mathrm{~s}$ of the pressure signals-nonuniform mixture. [Color figure can be viewed in the online issue, which is available at www.interscience.wiley. com.]

An increase in size of the pressure signal between

0 and $0.3 \mathrm{~s}$ is presented in Figure 6. One notes a first phase, of $0.062 \mathrm{~s}$ duration, where the pressure increases almost linearly upto an inflection point I1, marking a break in the slope. Beyond this point, the increase in pressure is linear upto a second inflection point, I2, at the time tb $(0.103 \mathrm{~s})$. The $\mathrm{I} 2$ point marks a second break in slope. Beyond $t b$, the pressure increases linearly to a maximum at P2, reached at tc (0.1456 s). Then, the pressure decreases exponentially until time $\operatorname{tr}(0.0586 \mathrm{~s})$, upto a final pressure value systematically smaller than the atmospheric pressure, typically about 0.7 bar.

A traditional model of combustion by sections was used. In a closed chamber, the inflammation of a gas pocket leads to the development of a flame front in both directions in the chamber. The combustion of each section by the flame front causes a compression of fresh and burned gas due to the expansion of the combustion products. In the burned gas, the progressive compression causes a highly increased tempera-

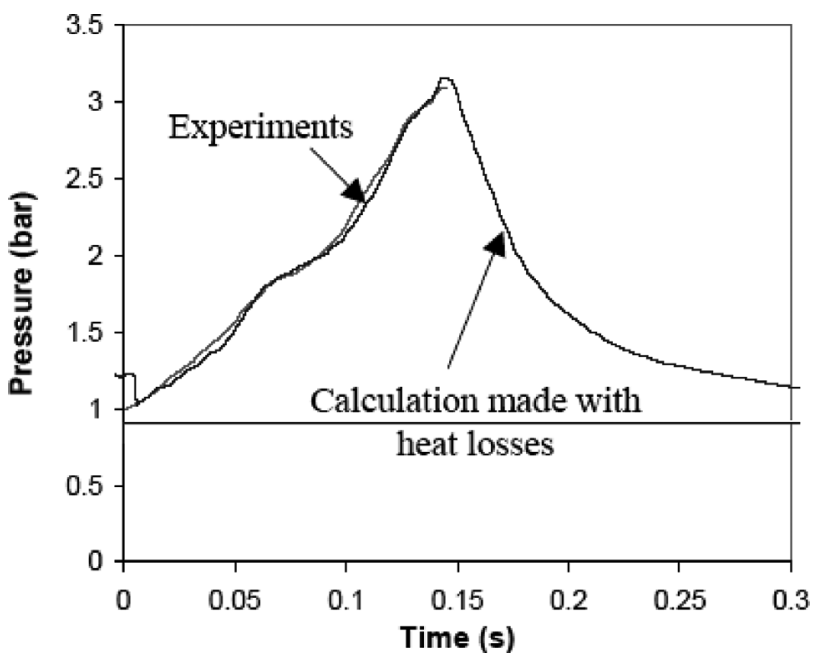

Figure 7. Pressure evolution versus time-nonuniform mixture. [Color figure can be viewed in the online issue, which is available at www.interscience.wiley.com.]

ture. In the fresh gas, the increasing pressure leads to a temperature increase as well, and due to the burned gas expansion, the gases are moving.

To calculate the thermodynamics parameters during the combustion, the following assumptions were considered:

- the gas follows the ideal gas law

- the combustion occurs at constant volume

- the gaseous mixture is divided into $N$ sections of the same mass

- the specific heat at constant pressure of the ideal gas is constant

- the pressure is the same at each point of the chamber at a given time.

Heat losses appear due to thermal and volume contractions of the gas and are conducive to a reduction in pressure effects. The combustion by sections model was adapted to our study by including thermal losses by conduction and condensation and the effect of mixture nonuniformities. First, each section of burned gas transfers heat to the wall by turbulent thermal conduction in a nonstationary regime. Second, each section of burned gas also transfers heat by a nonstationary flow of water vapor to the cold wall, where it condenses integrally.

By introducing the experimental flame trajectory into the model of combustion by sections, the pressure and the flame surface can be determined. The pressure signal calculated with this model is very well correlated with the experimental signal (Figure 7).

\section{FLAME PROPAGATION ANALYSIS}

\section{Flame Trajectory}

The flame propagation was deduced by exploiting high-speed video. A detailed analysis is possible by tracing the trajectory of the flame with time (Figure 8). 


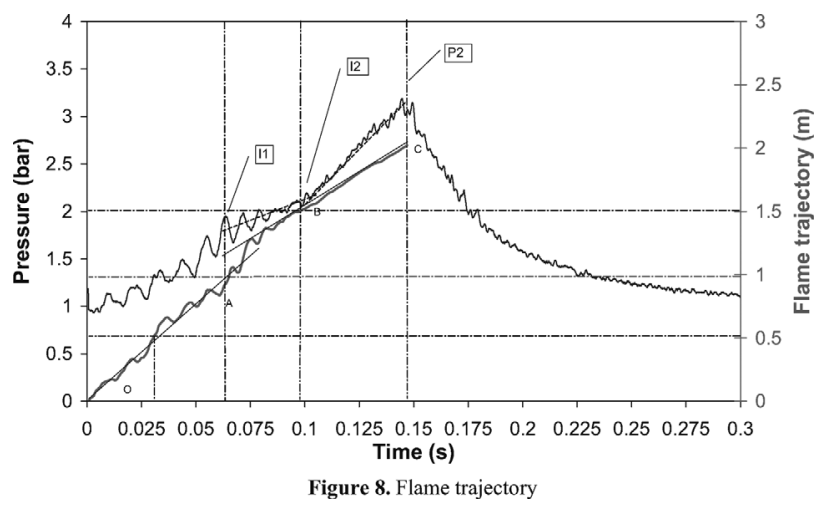

Figure 8. Flame trajectory. [Color figure can be viewed in the online issue, which is available at www.interscience.wiley.com.]

As for the pressure signal, an oscillation in the trajectory that is similar to the pressure oscillations is superimposed on the average evolution. These oscillations disappear after point $\mathrm{B}$, corresponding to the second inflection point I2. Three distinct modes appear during the flame propagation: between $\mathrm{O}$ and $\mathrm{A}, \mathrm{A}$ and $\mathrm{B}$, and $\mathrm{B}$ and $\mathrm{C}$. The sections $\mathrm{OA}$ to $\mathrm{BC}$ are characterized by a mean flame velocities of $13.5 \mathrm{~m} \mathrm{~s}^{-1}$ in section OA, $21.8 \mathrm{~m} \mathrm{~s}^{-1}$ in section $\mathrm{AB}$, and $10.5 \mathrm{~m} \mathrm{~s}^{-1}$ in section BC. Notably, between A and B, we observed a nonlinear increase in the propagation velocity.

It is also interesting that the mean flame velocity in section OA $(13.5 \mathrm{~m} / \mathrm{s})$, where the concentration of the mixture corresponds to M1, is similar to the flame velocity in section OA $\left(15.5 \mathrm{~m} \mathrm{~s}^{-1}\right)$ for the homogeneous mixture M1. However, the mean velocity in section BC $\left(10.5 \mathrm{~m} \mathrm{~s}^{-1}\right)$ is very different from the velocity at the end of propagation in the case of the homogeneous tests of the corresponding mixture M3 ( $\left.47 \mathrm{~m} \mathrm{~s}^{-1}\right)$.

The break in the flame trajectory coincides with the beginning of the gradient zone at $1 \mathrm{~m}$ in the direction of flame propagation.

\section{Flame Structure}

One can also extract the evolution of the flame surface with respect to the section of the tube according to the position of the flame (Figure 9).

The combustion by sections code made it possible to estimate the effects of compression on the size and the position of the gradient zone at the time of its interaction with the flame. The gradient zone extends $70 \mathrm{~cm}$, from 0.65 to $1.35 \mathrm{~m}$ (Figure 10). We calculated, using the combustion by sections code during the flame propagation, that the gradient zone is pushed about $30 \mathrm{~cm}$ toward the higher part of the tube, extending from 0.95 to $1.65 \mathrm{~m}$.

\section{COMPARISON OF COMBUSTION BETWEEN NONUNIFORM AND UNIFORM MIXTURES}

\section{Pressure Signals}

In the case of a nonuniform mixture (Figure 6), there is a difference in the high-frequency fraction of the signal compared with homogeneous mixtures.

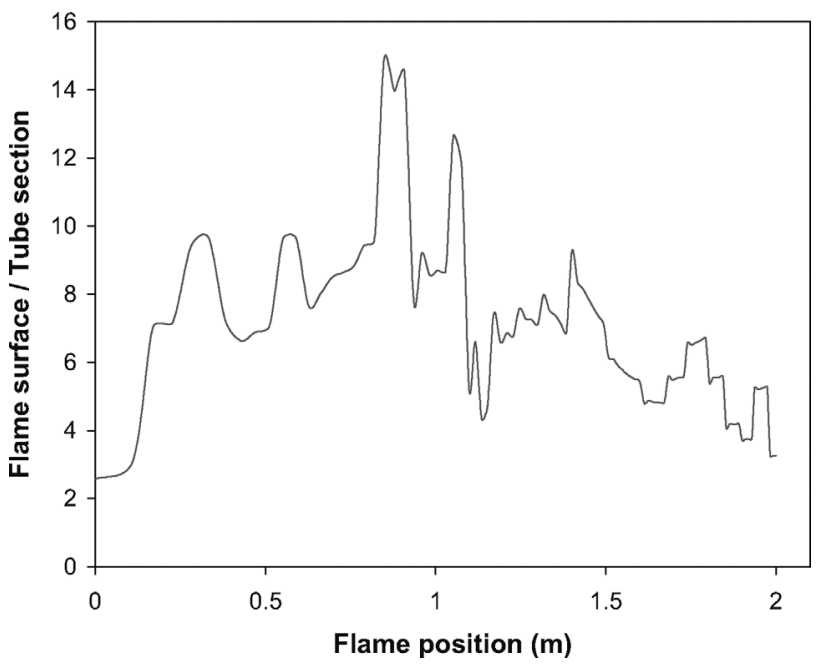

Figure 9. Ratio of the flame surface on the tube section-nonuniform mixture. [Color figure can be viewed in the online issue, which is available at www. interscience.wiley.com.]

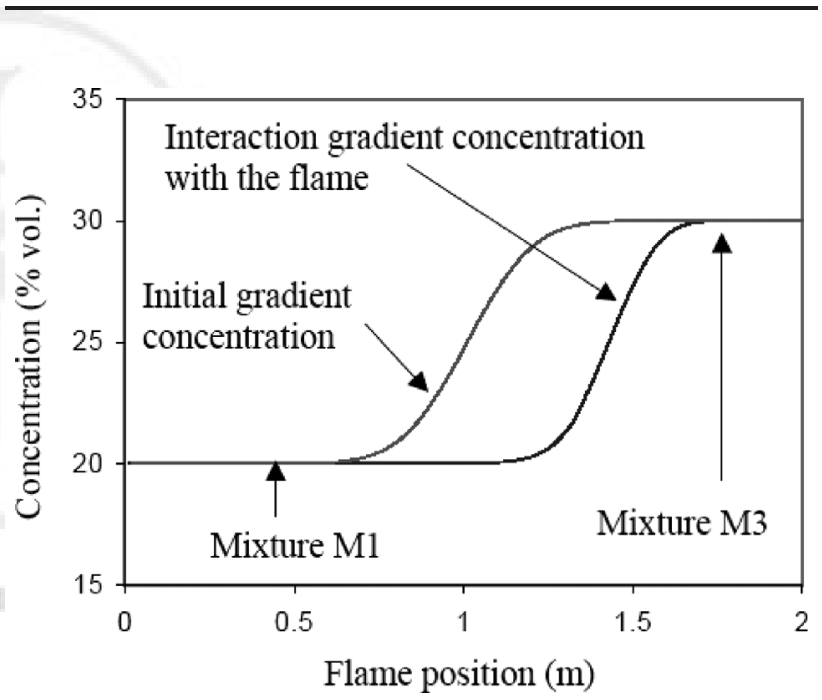

Figure 10. Interaction of gradient concentration with the flame-nonuniform mixture. [Color figure can be viewed in the online issue, which is available at www.interscience.wiley.com.]

With the nonuniform mixtures, the first and the third zones are identical to those of the homogeneous mixture. The first zone extends over $50 \mathrm{~ms}$ with frequency characteristics of 100 and $350 \mathrm{~Hz}$ and an amplitude of 50 mbar, whereas the third zone, extending from 90 to $147 \mathrm{~ms}$, presents an average frequency of $150 \mathrm{~Hz}$ and a low amplitude of 30 mbar. In contrast, in the second zone, ranging between 50 and $90 \mathrm{~ms}$ and presenting a frequency of $100 \mathrm{~Hz}$, there is a disappearance of the harmonics and a strong amplification of the amplitude of the oscillations (200 mbar) according to the fundamental mode.

A comparison of the envelope pressure signals for the heterogeneous mixture and the homogeneous mixtures M1, M2 (25\% vol. H2 + 13\% vol. O2 + 63\% 


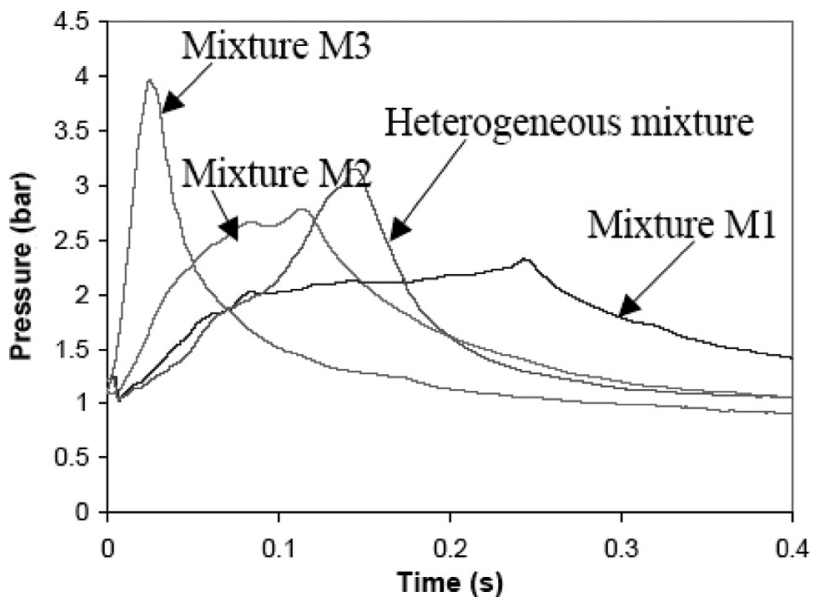

Figure 11. Pressure signals of uniform mixtures and nonuniform mixture. [Color figure can be viewed in the online issue, which is available at www. interscience.wiley.com.]

vol. N2), and M3 is presented in Figure 11. Even though each mixture contains the same quantity of reactants, the shape of the pressure signals differs, as well as the combustion times and the maximum pressures of the explosions. In particular, although the time of combustion is longer (256 ms, mixture M1; $114 \mathrm{~ms}$, mixture M2; $31 \mathrm{~ms}$, mixture M3; $147 \mathrm{~ms}$, nonuniform mixture), the maximum pressure of explosion is higher for the nonuniform mixture (3.1 bar, nonuniform mixture; 2.3 bar, mixture M1; 2.8 bar, mixture M2; 4.2 bar, mixture M3). This difference is more important with the mixture $\mathrm{M} 3$, which is present only in one small fraction of the tube. Heterogeneous mixtures compared with the homogeneous mixture M3, the explosion dynamics are significantly different, which could be explained by considering that during the ignition, the M3 mixture is present only in a small fraction of the tube (20 $\mathrm{cm}$ at top). The same can be said for the mixture M2. The pressure signals differ in form, combustion times, and maximum pressure. On first consideration, one might expect that the combustion times are different, since the M3 mixture is more reactive. However, it could also be the case that being present in the tube at the end of the propagation the M3 mixture would rather lead to suppression, similar to the case of the uniform mixture M3.

Nonuniform mixtures compared with the experiments with a uniform mixture M1, there is a good correlation of the signals upto $80 \mathrm{~ms}$ (i.e., until the $1.3 \mathrm{~m}$ position), which is explained by the presence of mixture M1 in the lower part of the tube. There is also a reasonable agreement between experimental flame surfaces and the model.

\section{Flame Surface}

When ignition occurs in the part of the tube where the composition is the M1 mixture, the excited frequencies are identical to those identified for the experiments undertaken with the homogeneous M1

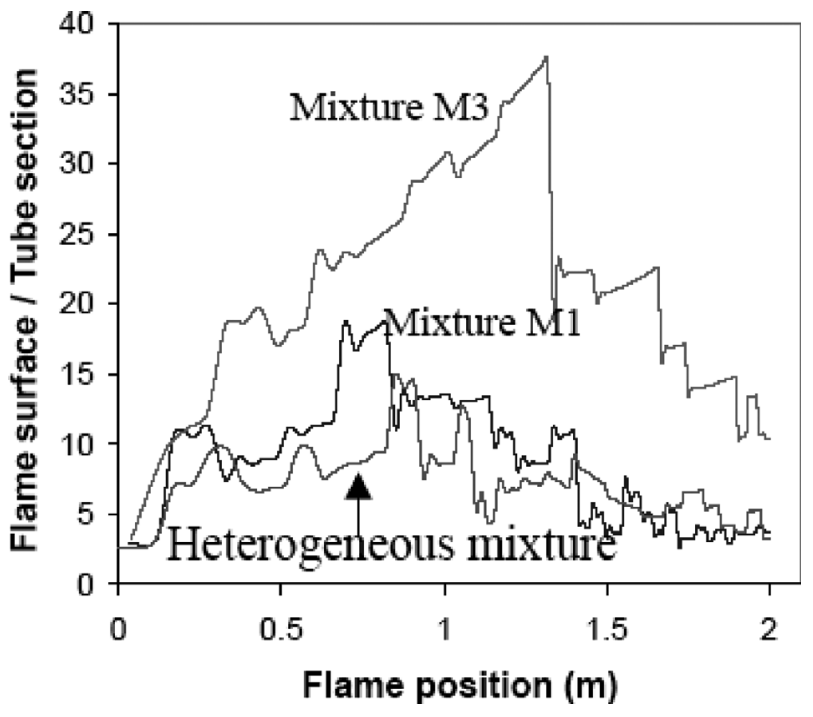

Figure 12. Flame surface/tube section for uniform mixtures and nonuniform mixture. [Color figure can be viewed in the online issue, which is available at www.interscience.wiley.com.]

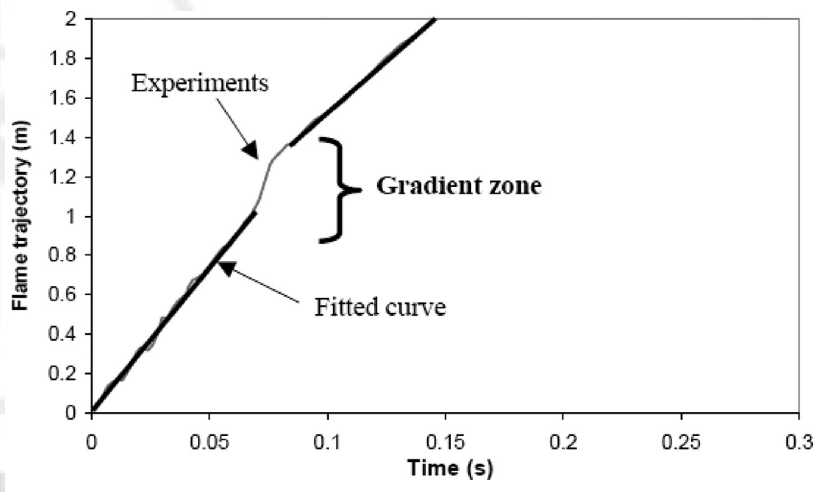

Figure 13. Flame trajectory-nonuniform mixture. [Color figure can be viewed in the online issue, which is available at www.interscience.wiley.com.]

mixture. The observation that the surface of the flame Af appears to be more dependent on the values of these frequencies and less on the equivalence ratio of the mixture explains why the evolutions in Af/At (At, tube area) appear similar for the heterogeneous mixture and the homogeneous mixture M1 (Figure 12). A significant difference in the evolution of flame surfaces implies a difference in the combustion rate.

However, the fundamental flame velocity and the burning rate are not constant during the propagation of the flame in the case of nonuniform mixtures (Figure 13), which is opposite to what is seen with the uniform mixtures. As the flame meets mixture M3 (in particular at the end of the propagation), for which the laminar flame velocity $S_{\mathrm{SI}}$ is about $2.5 \mathrm{~m} \mathrm{~s}^{-1}$ and the ratio Af/At is about 4 , it is calculated that the flame velocity should be $\sim 10 \mathrm{~m} \mathrm{~s}^{-1}$, which is in good agreement with the experiments $\left(10.53 \mathrm{~m} \mathrm{~s}^{-1}\right.$ in section BC). 
One can also interpret the jump in velocity between $\mathrm{A}$ and $\mathrm{B}$ in the trajectory of the flame in terms of the acceleration effect of the flame, since the velocity of expansion $\left(S_{1} a\right)$ increases from $4 \mathrm{~m} \mathrm{~s}^{-1}$ to $17 \mathrm{~m} \mathrm{~s}^{-1}$ over a length of $0.2 \mathrm{~m}$. Acceleration is calculated by: $(17-4)^{2} / 0.2=850 \mathrm{~m} \mathrm{~s}^{-2}$. By using the generalized Taylor model and a wavelength of disturbance equal to the diameter of the tube, one calculates that the flame must accelerate $20 \mathrm{~m} \mathrm{~s}^{-1}$ in this zone, which is in conformity with the observation.

\section{CONCLUSIONS}

In case of nonuniform mixtures, we observed a mode of flame propagation identical to that seen with homogenous mixtures; however, a third phase of propagation was also observed, where the flame velocity increases strongly. This increase could be due to the presence of a concentration gradient, which can very appreciably modify the trajectory and acceleration of a flame, according to the methods employed in this study that could be highlighted. The modest impact on pressure effects observed within the framework of this study likely result from the combustion being confined, which causes the final pressure to depend mainly on the quantity of reactants available and not on the mode of combustion. In other circumstances, in a partially confined enclosure or in a free atmosphere, the piston effect of the flame on the pressure effects is significant; thus, the impact of the concentration gradient could be much stronger.

\section{LITERATURE CITED}

1. A.C. Van den Berg, The multi-energy method, J Hazard Mater 12 (1985), 1-10.
2. J. Daubech, Ch. Proust, and I. Sochet, Flame front perturbations induced by concentration gradients, 6th ISHPMIE, Halifax, Canada, 2006.

3. Buncefield Major Incident Investigation, The Buncefield Investigation, Third Progress Report, Available at: http://www.buncefieldinvestigation.gov.uk.

4. P. Girard, M. Huneau, C. Rabasse, and J.C. Leyer, Flame propagation through unconfined and confined hemispherical stratified gaseous mixtures, Proceedings of the 17th International Symposium on Combustion, Combustion Institute, Pittsburgh, PA (1978), pp. 1247-1255.

5. G.A. Karim and V.P. Panlilio, Flame propagation and extinction within statified mixtures involving hydrogen and diluent inert gases in air, Vol. 2, Proceedings of the 9th World Energy Conference, Paris (1992), pp. 1191-1197.

6. D.R. Whitehouse, D.R. Greig, and G.W. Koroll, Combustion of stratified hydrogen-air mixtures in the $10.7 \mathrm{~m}^{3}$ combustion test facility cylinder, Nucl Eng Des 66 (1996), 453-462.

7. I. Sochet, P. Gillard, and F. Guelon, Effect of the concentration distribution on the gaseous deflagration propagation in the case of $\mathrm{H} 2 / \mathrm{O} 2$ mixture, J Loss Prev Process Ind 19 (2006), 250-263.

8. T. Hirano, T. Suzuki, I. Mashiko, and K. Iwai, Flame propagation through mixtures with concentration gradients, Proceedings of the 16th International Symposium on Combustion, Combustion Institute, Pittsburgh, PA (1977), pp. 1307-1315.

9. J. Daubech, I. Sochet, and Ch. Proust, Interaction of acoustic waves with flame front propagation, Process Saf Progr, DOI 10.1002/prs.10331. 
AQ1: Kindly check whether the expression " $S_{1} a$ " given here is OK?

AQ2: Kindly provide the volume number, year, and complete page range for Ref. 9. 